\title{
A TERCEIRIZAÇÃO NA ADMINISTRAÇÃO PÚBLICA: VANTAGENS, DESVANTAGENS E AMEAÇAS AO REGIME JURÍDICO DAS RELAÇÕES DO TRABALHO
}

\section{THE OUTSOURCING IN PUBLIC ADMINISTRATION: ADVANTAGES, DISADVANTAGES AND THREATS TO THE LEGAL REGIME OF LABOR RELATIONS}

\author{
Fernanda Maria Afonso Carneiro
}

\section{RESUMO}

Terceirização é uma técnica moderna de gestão em que atividades acessórias são repassadas a outras empresas. Sua utilização em maior escala foi determinada, quando as empresas, na tentativa de reduzir custos e melhorar a qualidade dos seus produtos e serviços prestados, passar a focar suas atenções nas atividades principais, desobrigando-se da execução direta das atividades secundárias. A terceirização tem sido utilizada com frequência pelo Estado. Este trabalho tem por objetivo fazer uma abordagem geral sobre a terceirização com ênfase na sua aplicação no setor público, investigando as possíveis ameaças aos regimes jurídicos de contratação de pessoal utilizados pelos entes estatais.

Palavras-chave: Administração Pública. Precarização. Trabalho. Terceirização. TST.

\begin{abstract}
Outsourcing is a modern management technique where ancillary activities are transferred to other companies. Its use on a larger scale was determined when companies, in an attempt to reduce costs and improve the quality of its products and services, go to focus their attention on core activities, disengaging from the direct execution of core activities. The outsourcing has been used frequently by the State. This paper aims to make a general approach on outsourcing with emphasis on its application in the public sector, investigating the possible threats to the legal staffing schemes used by state entities.
\end{abstract}

Keywords: Public Administration. Precariousness. Work. Outsourcing. TST.

\footnotetext{
${ }^{1}$ Doutora em Teoria Jurídico-Político e Relações Internacionais pela Universidade de Évora (Portugal). Coordenadora do Curso de Mestrado da Faculdade Paraíso do Ceará (FAP), Juazeiro do Norte/CE. (Brasil)

E-mail: fernandaafonsoadv@gmail.com
} 


\section{INTRODUÇÃO}

O processo de terceirização brasileiro teve início com a política desenvolvimentista colocada em prática no governo do presidente Juscelino Kubitschek (1955-1960), fundado na execução de um ousado Plano de Metas, cujo lema tinha como escopo levar o país a crescer "50 anos em 5". O ideal desenvolvimentista inserido no Plano de Metas foi consolidado em um conjunto de 30 objetivos a serem alcançados em diversos setores da economia, entre eles, implantar um parque industrial com foco na indústria automobilística.

Atraídos pelos incentivos oferecidos pelo governo federal, empresas multinacionais, como a Volkswagen, Ford, Willys, Toyota, Renault e Mercedes Benz, entre outras, instalaram-se no Estado de São Paulo. Essas montadoras de automóveis adotaram um modelo de produção até então desconhecido no país que visava produzir o maior número de unidades, para atender à demanda nacional em um menor tempo possível.

Para alcançar os objetivos traçados, a então recente indústria automobilística nacional dedicou-se, tão somente, à montagem dos automóveis, transferindo a fabricação das peças e demais componentes utilizados na produção de veículos, para empresas contratadas que passaram à condição de fornecedoras exclusivas para essas montadoras. A estratégia adotada pelas montadoras internacionais deu origem ao processo de terceirização no Brasil que, depois, seria disseminado por outros setores da economia nacional.

A terceirização no Brasil continuou em expansão, a partir do exemplo trazido pelas montadoras, sem que o Estado, no entanto, manifestasse qualquer preocupação com a regulamentação dessa atividade, fato que só veio a acontecer, de maneira incipiente, a partir do ano de 1974, quando o governo editou a Lei $\mathrm{n}^{\circ} 6.019$, que dispõe sobre o trabalho temporário nas empresas urbanas. Posteriormente, já no ano de 1983, portanto, quase 10 anos depois da primeira regulamentação, o governo federal voltou a cuidar do tema, ao editar a Lei $\mathrm{n}^{\circ} 7.102$ que tratou da segurança para estabelecimentos financeiros, estabelecendo normas para constituição e funcionamento das empresas particulares que exploravam serviços de vigilância e de transporte de valores. 
A ausência de uma regulamentação mais específica e abrangente, aliada ao aumento crescente na constituição de empresas especializadas na locação de mão-de-obra no país, fez com que o Tribunal Superior do Trabalho (TST) direcionasse sua preocupação para essa questão o que resultou na edição de duas Súmulas (de números 256 e 331), cujo objetivo era disciplinar, pelo menos no sentido amplo, a atividade de terceirização no país.

O presente trabalho tem como escopo maior a pretensão de realizar um estudo sobre o processo de terceirização, dando ênfase à sua aplicação na Administração Pública brasileira, analisando, principalmente, as ameaças que esse tipo de atividade pode representar para os regimes jurídicos aplicados no serviço público federal.

\section{ASPECTOS GERAIS DA TERCEIRIZAÇÃO}

A palavra "terceirização", oriunda da Ciência da Administração, é derivada da palavra "terceiro", que, para o interesse da Administração, corresponde à delegação de execução de atividades acessórias a terceiros, sendo adotada, posteriormente, pelo Direito sem que tenham sido feitos os devidos e necessários ajustes. De acordo com o que acentua Pereira (2013, p. 114), “a terceirização consubstancia uma relação jurídica triangular (trilateral), que envolve 3 atores e 3 relações jurídicas simultâneas". Ainda de acordo com os ensinamentos do referido autor, "os 3 atores sociais envolvidos são: a) Trabalhador; b) Empresa terceirizante (empresa prestadora dos serviços); e c) Empresa tomadora dos serviços (cliente)" (2013, p. 114).

Preocupado com o crescente aumento de demandas trabalhistas no setor, já que havia dúvida sobre quem deveria constar no pólo passivo, quando o autor da reclamação era o próprio trabalhador, se seria a empresa tomadora ou a própria empresa prestadora do serviço, o TST editou, no ano de 1986, a Súmula 256 que assim se manifestava:

\footnotetext{
Salvo os casos de trabalho temporário e de serviço de vigilância, previstos nas Leis $n^{\circ}$ 6.019, de 03.01.1974, e 7.102, de 20.06.1983, é ilícita a contratação de trabalhadores por empresa interposta, formando-se vínculo empregatício diretamente com o tomador de serviços.
}

Com a edição da Súmula acima citada, ficou pacificada a questão em relação à regulamentação do processo de terceirização no país, só sendo consideradas legais as 
atividades decorrentes do disposto nas Leis $\mathrm{n}^{\circ}$ 6.019/1974 e 7.102/1983, sendo todas as demais atividades consideradas ilícitas, imputando à empresa tomadora a responsabilidade por eventuais faltas no cumprimento das verbas trabalhistas devidas aos trabalhadores.

O que diferencia a terceirização lícita da ilícita é o caráter observado na relação contratual praticada entre a empresa tomadora e a empresa prestadora do serviço, qual seja, na terceirização lícita o que se tem de concreto é a prestação de um determinado serviço por uma empresa especializada para um empresa contratante, enquanto na ilícita ou que se observa é uma simples intermediação ou cessão de mão-de-obra de uma empresa para outra, o que, no entendimento de Resende (2014, p. 199), "fere os princípios basilares do Direito do Trabalho e a dignidade do trabalhador, o qual passa a ser tratado como mercadoria".

Delgado (2014, p. 467) esclarece que, “as situações-tipo de terceirização estão, hoje, claramente assentadas pelo texto da Súmula 331, TST”, sendo constituídas, de acordo com o referido autor, por "quatro grandes grupos de situações sociojurídicas delimitadas”. Esses quatro grandes grupos, ainda de acordo com o autor acima citado, são os seguintes:

a) Situações empresariais que autorizem contratação de trabalho temporário (Súmula 221, I, expressamente especificadas pela Lei n. 6.019/74); b) Atividades de vigilância, regidas pela Lei n. 7.102/83 (Súmula 331, III ab inítio); c) Atividades de conservação e limpeza (Súmula 331, III); d) Serviços especializados ligados à atividade-meio do tomador (DELGADO, 2014, p. 467).

Em consonância aos ensinamentos de Delgado (2014, p. 469), "excluídas as quatro situações-tipo acima examinadas, que ensejam a terceirização lícita no Direito brasileiro, não há na ordem jurídica do país preceito legal a dar validade trabalhista" a outra forma de relação de trabalho "sem que esse tomador responda, juridicamente, pela relação laboral estabelecida".

A definição do que seja atividade-meio e atividade-fim, no entanto, não é muito precisa e, em muitas situações, os conceitos acabam se confundindo, uma vez que não existe um regramento legal que defina, claramente, o que é uma ou outra atividade. A Súmula ${ }^{\circ} 331$ do TST, no seu inciso III, faz referência direta à atividade-meio, no entanto, em nenhum momento define o que seja essa espécie de atividade, restringindo-se, tão somente, a considerar a não formação de vínculo empregatício a contratação de "serviços especializados 
ligados à atividade-meio do tomador". Na seara doutrinária, Delgado traz as seguintes definições para atividade-fim e atividade-meio:

\begin{abstract}
Atividades-fins, ao reverso, são as atividades nucleares e definitórias da essência da dinâmica empresarial do tomador de serviços. Atividades-meios são as atividades periféricas à essência da dinâmica empresarial do tomador de serviços, ou seja, aquelas funções e tarefas empresariais e laborais que não se ajustam ao núcleo da dinâmica empresarial do tomador de serviços (DELGADO, 2014, p. 374).
\end{abstract}

Dessa forma, considerando-se as dificuldades levantadas quanto à questão da definição do que seja considerado uma atividade como fim ou meio, torna-se essencial, para a legalidade do processo, que a contratada tenha uma atividade definida, uma vez que, de acordo com entendimento do TST, no caso de uma determinada atividade ser objeto preponderante da atividade rotineira de um trabalhador, esta deve ser compreendida como sendo uma atividade-fim, conforme se observa no julgado a seguir relatado:

[...] Na realidade, não se pode dizer que a atividade de digitação é apenas meio no setor bancário, pois constitui ela, para os que laboram em caixas e compensação de cheques, a atividade primordial. Daí, por exemplo, a grande incidência da LER entre empregados de Bancos. Ora, se constitui essa atividade parte principal do cotidiano do bancário, não se pode considerá-la mera atividade-meio. Assim, por se tratar de atividade-fim, a terceirização permanente de mão-de-obra revela-se ilegal, quer segundo o ordenamento constitucional de 67, quer perante a Novel Carta Política. (ROAR - 804604-93.2001.5.05.5555, Relator Ministro: Ives Gandra Martins Filho, Data de Julgamento: 20/08/2002, Subseção II Especializada em Dissídios Individuais, Data de Publicação: 27/09/2002).

Na prática, o que se observa é que a verificação da atividade-fim da empresa é feita através da análise do seu contrato social. Se o empregado realiza alguma atividade que contribua para a produção do objeto social da empresa, este não presta serviço terceirizado e poderá ter o vínculo empregatício com o tomador de serviços reconhecido, conforme determinado pela Súmula 331 do TST.

\title{
2. A TERCEIRIZAÇÃO NA ADMINISTRAÇÃO PÚBLICA: ASPECTOS GERAIS
}

A expressão Administração Pública é utilizada quando se pretende referenciar o conjunto de entes, bem como as diversas entidades e instituições que fazem parte da função administrativa, sendo que, como objeto essencial do Direito Administrativo, os organismos que a compõem estão inseridos no Poder Executivo. De acordo com Justen Filho (2014, p. 
266), "a expressão em si comporta dois sentidos, um objetivo e outro subjetivo", sendo que, “em sentido objetivo a Administração Pública é o conjunto de bens e direitos necessários ao desempenho da função administrativa", enquanto que, "numa acepção subjetiva, Administração Pública é o conjunto de pessoas, públicas e privadas, e de órgãos que exercitam atividade administrativa".

Importante ressaltar, portanto, que, em um primeiro momento, ao optar por transferir atividades para que outras entidades a executassem, a Administração Pública utilizou-se do processo de descentralização administrativa, repassando, portanto, algumas atividades que lhe cabia desempenhar, para órgãos integrantes da sua própria estrutura organizacional, mas que atua de forma indireta, com personalidade jurídica própria, e que nada mais são do que pessoas jurídicas distintas, criadas com uma finalidade específica, mas, sendo elas, por determinação constitucional, pertencentes à estrutura organizacional da própria Administração Pública direta. Com relação ao posicionamento acima destacado Justen Filho esclarece que:

Uma lei pode transferir uma parcela da competência da União para uma autarquia. A autarquia é dotada de personalidade jurídica própria, o que significa ser ela pessoa jurídica distinta do ente que a criou. Então, alude-se à descentralização para indicar um processo de distribuição de competências entre sujeitos de direitos diversos (JUSTEN FILHO, 2014, p. 273).

O processo de terceirização na Administração Pública brasileira não se trata de um procedimento que possa ser apontado como uma característica do momento atual, portanto, que tenha o condão de ser compreendido como algo inovador, ou provocado pelas exigências que o mundo, altamente globalizado de agora, impõe, como resultado da quase completa integração dos mercados nos seus diferentes níveis e setores. Com efeito, o Decreto-Lei ${ }^{\circ}$ 200/1967, no seu art. 10, parágrafo $7^{\circ}$, já prevê no seu ordenamento a possibilidade de a Administração Pública desincumbir-se das atividades não relacionadas, diretamente, ao seu objeto finalístico, que é a prestação de serviços públicos, transferindo a execução dessas atividades assim compreendidas, para empresas prestadoras de serviços, mediante contrato e desde que satisfeitas algumas condições específicas, conforme se observa no seu enunciado.

Art. 10. A execução das atividades da Administração Federal deverá ser amplamente descentralizada.

$\S 7^{\circ}$ Para melhor desincumbir-se das tarefas de planejamento, coordenação, supervisão e controle e com o objetivo de impedir o crescimento desmesurado da 
máquina administrativa, a Administração procurará desobrigar-se da realização material de tarefas executivas, recorrendo, sempre que possível, à execução indireta, mediante contrato, desde que exista, na área, iniciativa privada suficientemente desenvolvida e capacitada a desempenhar os encargos de execução.

A complexidade em relação ao estudo do processo de terceirização na Administração Pública consubstancia-se face à obediência aos princípios regentes do Direito Administrativo e ao respeito ao que preceitua as regras do procedimento licitatório estabelecido pela Lei $\mathrm{n}^{\circ}$. 8.666/1993 que institui normas para as licitações e para os contratos firmados pela Administração Pública, ao mesmo tempo em que regulamenta o artigo 37, inciso XXI, da Constituição Federal de 1988, cujo enunciado é o seguinte:

Art. 37. A administração pública direta e indireta de qualquer dos Poderes da União, dos Estados, do Distrito Federal e dos Municípios obedecerá aos princípios de legalidade, impessoalidade, moralidade, publicidade e eficiência e, também, ao seguinte:

XXI - ressalvados os casos especificados na legislação, as obras, serviços, compras e alienações serão contratados mediante processo de licitação pública que assegure igualdade de condições a todos os concorrentes, com cláusulas que estabeleçam obrigações de pagamento, mantidas as condições efetivas da proposta, nos termos da lei, o qual somente permitirá as exigências de qualificação técnica e econômica indispensáveis à garantia do cumprimento das obrigações.

De uma maneira bastante distinta ao que acontece na iniciativa privada, a contratação irregular de um trabalhador, mediante contrato firmado com uma empresa interposta, não gera vínculo de emprego diretamente com a Administração Pública. Esse fato ocorre porque é exigida a realização de concurso público para a contratação de trabalhador pela Administração Pública direta e indireta, conforme dispõe o inciso II do artigo 37 da Constituição Federal de 1988 que, com o fito de estabelecer regramento para a contratação de servidor público, assim se manifesta:

\footnotetext{
Art. $37(\ldots)$

II - a investidura em cargo ou emprego público depende de aprovação prévia em concurso público de provas ou de provas e títulos, de acordo com a natureza e a complexidade do cargo ou emprego, na forma prevista em lei, ressalvadas as nomeações para cargo em comissão declarado em lei de livre nomeação e exoneração.
}

Dessa forma, a inobservância a esse dispositivo constitucional torna nulo de pleno direito qualquer contratação realizada pela Administração Pública direta ou indireta, conforme estampado no parágrafo $2^{\circ}$ do artigo supracitado que dispõe que "a não observância do 
disposto nos incisos II e III implicará a nulidade do ato e a punição da autoridade responsável, nos termos da lei”. Nesse sentido, a Súmula $n^{\circ} 363$, do TST, com a nova redação data pela Resolução no 121/2003, sustenta que:

CONTRATO NULO. EFEITOS - A contratação de servidor público, após a CF/1988, sem prévia aprovação em concurso público, encontra óbice no respectivo art. 37, II e $\S 2^{\circ}$, somente lhe conferindo direito ao pagamento da contraprestação pactuada, em relação ao número de horas trabalhadas, respeitado o valor da hora do salário mínimo, e dos valores referentes aos depósitos do FGTS.

Nessa mesma direção, a Súmula $n^{\circ}$ 685, do Supremo Tribunal Federal (STF) estabelece que "é inconstitucional toda modalidade de provimento que propicie ao servidor investir-se, sem prévia aprovação em concurso público destinado ao seu provimento, em cargo que não integra a carreira na qual anteriormente investido". Não obstante ocorra o impedimento constitucional para a contratação sem a realização do competente e necessário concurso público, a eventual contratação irregular de trabalhador, mediante empresa interposta, mesmo não implicando na construção de vínculo empregatício com a Administração Pública, é cediço que ao empregado terceirizado caiba o direito às mesmas verbas trabalhistas legais asseguradas aos contratados. Em consonância com o art. 37, inciso II da Constituição Federal de 1988, desde que, evidentemente, esteja patente a igualdade de funções, situação essa obtida, evidentemente, graças à aplicação do princípio da isonomia e ao cumprimento ao que estabelece a Lei $\mathrm{n}^{\circ}$ 6.019/1974, em seu art. 12, letra "a" que assim se manifesta:

Art 12. Ficam assegurados ao trabalhador temporário os seguintes direitos: a) remuneração equivalente à percebida pelos empregados de mesma categoria da empresa tomadora ou cliente calculados à base horária, garantida, em qualquer hipótese, a percepção do salário-mínimo integral.

A aplicação do princípio da isonomia nesse caso específico busca evitar algum tipo de discriminação de natureza social e econômica que, porventura, viesse a ser praticada pela Administração Pública, utilizando-se, equivocadamente, do processo de terceirização para reduzir salários de quem lhe presta serviços laborais, o que violaria, de maneira enfática e 
inoportuna, o art. 5 , caput, da Constituição Federal. Ademais, a Lei nº 6.019/1974 teve a preocupação de estabelecer a equivalência salarial entre trabalhadores de idêntica categoria, independente de manter vínculo com o tomador ou prestador do serviço, como forma de garantir os direitos de quem labora para outrem mediante contrato firmado com a empresa ao qual pertence, obedecendo, portanto, ao disposto no art. $7^{\circ}$, inciso XXX da Constituição Federal de 1988. Outra questão a ser considerada nessa relação diz respeito à responsabilidade pelo pagamento dos direitos trabalhistas que, eventualmente, não venha a ser honrado pela empresa prestadora do serviço. Para isentar a Administração Pública dessa responsabilidade direta, a Lei nº 8.666/1993 (Lei de Licitações e Contratos), no seu art. 71, § 1º, com redação dada pela Lei $n^{\circ}$ 9.032/1995, estabelece que:

A inadimplência do contratado, com referência aos encargos trabalhistas, fiscais e comerciais não transfere à Administração Pública a responsabilidade por seu pagamento, nem poderá onerar o objeto do contrato ou restringir a regularização e o uso das obras e edificações, inclusive perante o Registro de Imóveis.

Apesar de a legislação determinar a não transferência da responsabilidade dos encargos trabalhistas para a Administração Pública, Pereira esclarece que:

Não obstante o art. 71, caput, e $\S 1^{\text {o }}$ da Lei 8.666/1993 afastar qualquer responsabilidade trabalhista da Administração Pública, prevalece o entendimento de sua responsabilidade subsidiária, em virtude da culpa in eligendo e in vigilando proveniente da licitação, ou seja, a culpa na escolha do contratado e na fiscalização de suas atividades (PEREIRA, 2013, p. 117).

\section{VANTAGENS E DESVANTAGENS DA TERCEIRIZAÇÃO NA ADMINISTRAÇÃO PÚBLICA}

Para alguns doutrinadores, a terceirização de determinadas atividades na Administração Pública permite que o ente estatal possa se dedicar com maior afinco às atividades que lhe são peculiares, além de servir como um instrumento capaz de solucionar, ainda que temporariamente, a falta de pessoal no serviço público, muitas vezes provocada pela demora, em algumas situações de forma excessiva, na realização de concurso público para contratação de novos servidores. Essa demora, quase sempre, segundo os doutrinadores, é decorrente do contingenciamento de verbas por parte do governo federal, tendo como consequências mais visíveis, a perda na qualidade do serviço público prestado, por falta de 
pessoal para executar as atividades inerentes à função pública. Dessa forma, a deficiência na prestação do serviço público de qualidade poderia ser, segundo essa corrente que defende a terceirização na Administração Pública, suprida através da contratação de empresa prestadora de serviços, sem que essa prática se configure como uma transferência de uma atividade afeita ao Poder Público para uma empresa privada, cujo objetivo maior é almejar o lucro.

Por outro lado, a prática descontrolada e intensiva da terceirização na Administração Pública poderia fazer com que o Estado se tornasse completamente dependente dos serviços executados pelas empresas prestadoras de serviços. Essa dependência seria inevitável, uma vez que o Estado abriria mão de realizar concurso público para contratação de pessoal, preferindo contratar empresas para substituir a mão-de-obra direta. No entanto, em que pese essa possibilidade, há de se observar, fundamentando-se na mesma premissa, que empregados terceirizados não podem substituir, nas atividades especializadas, aqueles que são contratados mediante aprovação em concurso público. Em apoio a essa colocação, Delgado, com muita propriedade, invocando a Carta Magna, esclarece que:

\footnotetext{
A Constituição de 1988 lançou uma especificidade no tocante aos efeitos jurídicos da terceirização efetuada por entidades da administração pública direta, indireta e fundacional. É que a Constituição colocou a aprovação prévia em concurso público de provas ou de provas e títulos como requisito insuplantável para a investidura em cargo ou emprego público, considerando nulo o ato de admissão efetuado sem a observância de tal requisito (art. 37, II e $§ 2^{\circ}$, CF/88) (DELGADO, 2014, p. 473).
}

A restrição constitucional, portanto, constitui-se em óbice intransponível a uma possível pretensão da Administração Pública de tentar substituir servidor público por empregado terceirizado ainda que seja sob a alegação de que ocorra escassez de mão-de-obra para realizar atividades típicas do ente estatal. Assim sendo, qualquer ação nesse sentido é considerado um ato nulo de pleno direito, caracterizado pela ocorrência de contratação irregular de mão-de-obra.

Em que pese o dispositivo constitucional acima destacado, Santos (2008, p. 136), considera que o parágrafo $7^{\circ}$, do art. 10 do Decreto-Lei $n^{\circ}$ 200/1967, “deu permissão à Administração Pública para terceirizar a prestação de serviços públicos para empresas privadas especializadas". Em análise sintética a respeito das vantagens e desvantagens advindas da aplicação do processo de terceirização na Administração Pública, Flores dos Santos destaca com muita propriedade que: 
Assim, pode-se afirmar que, a depender da especificidade do ativo, a terceirização pode se tornar eficiente para a Administração Pública, cabendo analisar cada caso, não se podendo estabelecer, a priori, quando se pode terceirizar ou não. Entretanto, se o nível de investimento for de tal ordem que não possa ser reutilizado, pode-se configurar, além de um aumento de custos de transação, também uma dependência do tomador de serviços com alguns trabalhadores terceirizados, o que não se revela eficiente, porquanto afeta diretamente também a competência essencial da organização [...] (FLORES DOS SANTOS, 2014, p. 580).

\section{REGIMES JURÍDICOS DE CONTRATAÇÃO DE PESSOAL NA ADMINISTRAÇÃO PÚBLICA}

O regime jurídico representa o conjunto de normas relacionadas aos deveres, direitos e demais aspectos da vida funcional do servidor público, ou, conforme os ensinamentos de Carvalho Filho (2011, p. 602), "é o conjunto de regras de direito que regulam determinada relação jurídica", originando-se desse regime, segundo o doutrinador, "diversos direitos e deveres para os servidores públicos". O requisito básico para o acesso a cargos públicos, obedecidos aos princípios da legalidade, impessoalidade, moralidade e isonomia, é o concurso público, de provas ou de provas e títulos, uma vez que os critérios de seleção são objetivos, conforme dispõe a Constituição Federal de 1988 (CF/88), no seu artigo 37, inciso II.

Atualmente são aplicados na Administração Pública dois regimes jurídicos, o que dispõe sobre o regime dos servidores públicos da administração direta, das autarquias e das fundações públicas, regidas pelo direito público, chamado Regime Estatutário, e o que disciplina o regime de emprego público nas empresas estatais (empresas públicas e sociedades de economia mista) e fundações públicas regidas pelo direito privado, denominado Regime Celetista ou Regime Trabalhista e que, portanto, obedece à mesma orientação normativa estampada na Consolidação das Leis do Trabalho (CLT), comum aos trabalhadores das empresas privadas. De acordo com Carvalho Filho (2011, p. 603), o regime estatutário regula "a relação funcional entre o servidor público estatutário e o Estado". O referido autor destaca, também que "cada pessoa da federação, desde que adote o regime estatutário para os seus servidores, precisa ter a sua lei estatutária para que possa identificar a disciplina da relação jurídica funcional entre as partes" (2011, p. 603).

No regime estatutário, a relação entre servidor e Estado não tem natureza contratual, ou seja, conforme explica Carvalho Filho (2011, p. 603), "inexiste contrato entre o Poder Público e o servidor estatutário". Cumpre esclarecer por oportuno que, para fins de estudo do presente trabalho, só será considerado, em relação ao regime dos servidores públicos da administração direta, das autarquias e das fundações públicas, regidas pelo direito público, 
aquele que regulamenta as atividades dos servidores públicos federais, uma vez que os demais entes federativos, Estados, Distrito Federal e Municípios, apresentam, cada um deles, regramentos próprios relacionados às atividades dos servidores públicos, sejam eles estatutários ou celetistas.

O regime estatutário aplicado ao serviço público federal, e aqui considerado, é aquele em que os direitos, deveres e demais aspectos da vida funcional do servidor estatutário estão consubstanciados na lei $\mathrm{n}^{\mathrm{o}} 8.112 / 1990$, chamada de Estatuto do Servidor Público, que traz a seguinte definição a respeito do servidor estatutário que se relaciona com o serviço público federal:

Servidores Estatutários são aqueles agentes públicos que têm vínculo permanente, de natureza profissional, por prazo indeterminado, sem a celebração de contrato de emprego e que, submetidos a concurso público, venham prestar serviços à Administração Pública direta, às autarquias $\mathrm{e}$ as fundações públicas (Lei $\mathrm{n}^{\mathrm{o}}$ 8.112/1990).

O servidor estatutário habilitado em concurso público e empossado em cargo de provimento efetivo adquire estabilidade no serviço público ao completar 3 (três) anos de efetivo exercício e só perderá o cargo em virtude de sentença judicial transitada em julgado ou de processo administrativo disciplinar no qual lhe seja assegurada ampla defesa, conforme estabelece os arts. 21 e 22 da Lei $n^{\circ} 8.112 / 1990$ e art. 41 da CF/88.

No regime celetista ou trabalhista, os direitos e deveres dos servidores públicos, de todos os entes federativos (União, Estados, Distrito Federal e Municípios) são norteados pela CLT e, de acordo com Carvalho Filho (2011, p. 605), "as características desse regime antagonizam com as do regime estatutário". Primeiro porque, diferente do que ocorre no regime estatutário, onde cada ente federativo tem o seu próprio estatuto, no regime celetista ou trabalhista, existe, tão somente, um único diploma legal, a CLT, que regula, também, as relações entre o servidor público e o Estado, seja ele a União, os Estados, o Distrito Federal ou os Municípios.

A Lei $\mathrm{n}^{\circ} 9.962 / 2000$, que trata dos servidores celetistas federais, trata-se de uma lei curta, com 5 artigos apenas, uma vez que as relações de emprego estão submetidas ao regime da CLT, diferentemente, conforme já explicitado, dos servidores estatutários que dispõem de regime próprio. Servidores celetistas federais, portanto, são aqueles que mantém vínculo 
permanente com a União, por prazo indeterminado, sob a relação de emprego, sendo-lhes aplicado o regime da CLT, conforme dispõe o art. $1^{\circ}$ da lei $n^{\circ} 9.962 / 2000$ que assim se manifesta:

Art. $1^{\circ} \mathrm{O}$ pessoal admitido para emprego público na Administração federal direta, autárquica e fundacional terá sua relação de trabalho regida pela Consolidação das Leis do Trabalho, aprovada pelo Decreto-Lei $n^{\circ} 5.452$, de $1^{\circ}$ de maio de 1943 , e legislação trabalhista correlata, naquilo que a lei não dispuser em contrário.

Os servidores celetistas, ao contrário dos servidores estatutários, não gozam da prerrogativa da estabilidade, conforme preceitua a Súmula 390 do TST, ao estabelecer que "ao empregado de empresa pública ou de sociedade de economia mista, ainda que admitido mediante aprovação em concurso público, não é garantida a estabilidade prevista no art. 41 da CF/88". No entanto, apesar da ausência da estabilidade, é discutível a dispensa imotivada do servidor celetista. Nesse sentido, o Supremo Tribunal Federal (STF) já se posicionou que é imprescindível a justificativa para dispensa dos empregados das empresas estatais, ao julgar o Recurso Extraordinário (RE) no 589.998-PI, em setembro de 2013, assim sentenciado:

\begin{abstract}
EMPRESA BRASILEIRA DE CORREIOS E TELÉGRAFOS - ECT. DEMISSÃO IMOTIVADA DE SEUS EMPREGADOS. IMPOSSIBILIDADE. NECESSIDADE DE MOTIVAÇÃO DA DISPENSA. RE PARCIALEMENTE PROVIDO. I - Os empregados públicos não fazem jus à estabilidade prevista no art. 41 da $\mathrm{CF}$, salvo aqueles admitidos em período anterior ao advento da EC no 19/1998. Precedentes. II - Em atenção, no entanto, aos princípios da impessoalidade e isonomia, que regem a admissão por concurso público, a dispensa do empregado de empresas públicas e sociedades de economia mista que prestam serviços públicos deve ser motivada, assegurando-se, assim, que tais princípios, observados no momento daquela admissão, sejam também respeitados por ocasião da dispensa. III - A motivação do ato de dispensa, assim, visa a resguardar o empregado de uma possível quebra do postulado da impessoalidade por parte do agente estatal investido do poder de demitir. IV - Recurso extraordinário parcialmente provido para afastar a aplicação, ao caso, do art. 41 da CF, exigindo-se, entretanto, a motivação para legitimar a rescisão unilateral do contrato de trabalho.' (RE 589998/PI - PIAUÍ, RECURSO EXTRAORDINÁRIO, Relator(a): Min. RICARDO LEWANDOWSKI, Órgão Julgador: Tribunal Pleno, Julgamento: 20/03/2013, Dje-179, Divulgado em1 1/09/2013, Publicado em 12/09/2013 i).
\end{abstract}

A partir do julgamento do RE $n^{\circ}$ 589.998-PI, pelo Supremo Tribunal Federal, o Tribunal Superior do Trabalho passou a observar o entendimento daquele egrégio colégio, conforme se observa no seguinte julgamento:

RECURSO DE REVISTA. SOCIEDADE DE ECONOMIA MISTA. DISPENSA. MOTIVAÇÃO. NECESSIDADE. 1. O Tribunal Pleno do Supremo Tribunal 
Federal, no julgamento do Recurso Extraordinário no 589.998-PI (Rel. Min. RICARDO LEWANDOWSKI, DJe de 11/9/2013), consagrou o entendimento de que os servidores de empresas públicas e sociedades de economia mista, admitidos por concurso público, não gozam da estabilidade preconizada no art. 41 da Constituição Federal, mas sua dispensa deve ser sempre motivada. 2. Tal entendimento pautou-se na necessidade de observância, pela Administração Pública, dos princípios constitucionais da legalidade, isonomia, moralidade e impessoalidade, insculpidos no art. 37, caput, da Constituição Federal. 3. Recurso de revista de que não se conhece.” (Processo: RR - 108200-97.2009.5.01.0078 Data de Julgamento: 14/05/2014, Relator Ministro: João Oreste Dalazen, $4^{\text {a }}$ Turma, Data de Publicação: DEJT 30/05/2014 -).

O TST confirmou seu posicionamento em recente decisão, entretanto, considerou que a motivação para a dispensa do servidor celetista, cabe, tão somente, aos empregados que foram admitidos mediante concurso público, conforme se observa a seguir:

AGRAVO DE INSTRUMENTO EM RECURSO DE REVISTA. DISPENSA IMOTIVADA. EMPREGADO DE SOCIEDADE DE ECONOMIA MISTA ADMITIDO SEM CONCURSO. DESNECESSIDADE DE MOTIVAÇÃO DO ATO DEMISSIONAL. Hipótese na qual o empregado de Sociedade de Economia Mista, admitido sob a égide da Constituição Federal de 1988, sem ter realizado concurso público, é dispensado sem justo motivo. A peculiaridade de não ter o agravante sido admitido mediante concurso público afasta a possibilidade de aplicação do entendimento consagrado pelo ex. STF acerca da vedação de dispensa de empregado de Sociedade de Economia Mista sem motivação. Ausência de afronta às normas invocadas pelo agravante. Agravo de instrumento conhecido e desprovido. (AIRR 934-36.2010.5.01.0007).

Apesar da existência de dois regimes jurídicos distintos, como o empregador trata-se do próprio ente estatal, alguns preceitos contidos no regime jurídico estatutário, estampados no art. 37 da Constituição Federal de 1988, são estendidos aos servidores públicos regidos pelo regime jurídico celetista. São exemplos dessa extensão, o limite da remuneração (inciso XI); a proibição de acumulação remunerada de outro emprego, cargo ou função (inciso XVII), a possibilidade de sofrer sanções por improbidade administrativa $\left(\S 4^{\circ}\right)$ e Lei $n^{\circ} 8.429 / 1992$, art. $1^{\circ}$.

\section{AMEAÇAS DA TERCEIRIZAÇÃO AOS REGIMES JURÍDICOS DA ADMINISTRAÇÃO PÚBLICA}

No âmbito da Administração direta, autárquica e fundacional, a terceirização encontra-se bastante ampliada, abrangendo grande parte das atividades de apoio aos 
respectivos órgãos e entidades. Assim sendo, a terceirização se coloca, hoje, como uma opção para o exercício, pela Administração Pública, de um grande número de atividades de caráter acessório, nas quais não existam os requisitos da permanência e da continuidade. No entanto, o processo de terceirização no serviço público tem sido objeto de grande controvérsia e forte crítica uma vez que se deve considerar que a Administração Pública está contratando serviços, e não pessoal, quando promove terceirização.

Assim, em primeiro e fundamental lugar, o instituto não pode ser usado como forma de burla do concurso público. Efetivamente, utilizar terceirização como forma de admitir pessoal, evitando-se o princípio da impessoalidade, pode deturpar todo o processo que a envolve. O processo de terceirização no serviço público brasileiro adquiriu uma característica de legalidade como instrumento capaz de diminuir o tamanho do Estado, conforme se depreende, inclusive, do exposto em relatório do Departamento Intersindical de Estatísticas e Estudos Socioeconômicos (DIEESE), ao esclarecer que:

\begin{abstract}
Juridicamente, a terceirização no setor público é um recurso legal e contratual de transferência da responsabilidade de alguns serviços a empresas privadas, nacionais ou multinacionais, cooperativas de trabalho, Organizações da Sociedade Civil de Interesse Público (Oscips), Organizações Sociais (OSs) e Organizações NãoGovernamentais (ONGs) sendo, necessariamente, precedida por licitação disciplinada pela Lei 8.666/93 e pelas leis que posteriormente a alteraram (DIEESE, 2013, p. 25).
\end{abstract}

Ainda de acordo com o referido relatório do DIEESE, "via licitação, a administração pública pode delegar atividades a uma empresa, não havendo nenhum vínculo de subordinação entre o trabalhador da prestadora de serviços e o órgão/entidade pública" (2013, p. 26). No entanto, o processo de terceirização aplicado no setor público, assim como ocorre no setor privado, tem apresentado distorções em relação à remuneração do trabalhador, uma vez que, pode não ser cumprido o princípio da isonomia salarial na Administração Pública, principalmente, porque, via de regra, os trabalhadores terceirizados são contratados com salários menores que os praticados aos servidores efetivos. Além das distorções salariais, alguns benefícios ou vantagens, conhecidos por salários indiretos, como auxílio alimentação, vale transporte, assistência médico-odontológica, entre outros, oferecidos aos servidores efetivos, costumam não ser disponibilizados aos terceirizados, o que contribui, sobremaneira, para aumentar o fosso entre os salários efetivamente pagos às duas categorias profissionais. Nesse sentido, de acordo com o relatório do DIEESE, acima referenciado: 


\begin{abstract}
A terceirização no setor público nos variados campos tem se colocado como uma alternativa para a flexibilização da gestão do trabalho, apesar de ser uma opção administrativa extremamente polêmica e, não raro, perversa para os trabalhadores. Além disso, do ponto de vista do serviço prestado, a questão relevante é a de escolher quais os setores ou funções que, terceirizados, resultaria não somente em redução de custos, mas também em melhoria, agilização e aumento da qualidade desses serviços. Resta mencionar as dificuldades inerentes à especificação e ao monitoramento dos resultados almejados por meio do mecanismo de terceirização. Os resultados devem ser avaliados não apenas sob uma ótica estritamente técnica, pois sua definição deveria também ser permeada pelas expectativas de atendimento qualificado dos maiores interessados: os cidadãos-usuários (DIEESE, 2013, p. 39).
\end{abstract}

Outro fator importante a considerar relaciona-se à possibilidade de ocorrência de algum tipo de burla à Constituição Federal de 1988, no que concerne à contratação de servidores, seja para executar atividade-meio ou atividade-fim. A Carta Magna veda, no inciso II, do artigo 37, a investidura em cargo ou emprego público sem a devida aprovação em concurso público. O expediente da terceirização, portanto, pode vir a ser utilizado para a contratação de determinados trabalhadores especializados, sob a justificativa de que a oferta salarial poderia ser fator impeditivo para a contratação regular mediante concurso público, ensejando, portanto, a adoção da contratação através do processo de terceirização. Nesse sentido, Flores dos Santos apresenta o seguinte exemplo:

[...] fatores dificultadores de contratação, como seleção pública por intermédio de concurso público (considerando o art. 37, II, da Constituição da República) e baixa atratividade remuneratória de Procuradores (considerando o teto remuneratório ser o subsídio do Prefeito, conforme o art. 37, IX, da Constituição da República), pode ser que para o órgão seja conveniente terceirizar visando sanar uma contingência atual (embora isso não seja o ideal, pois se estende que esse tipo de serviço é estratégico para a organização) (FLORES DOS SANTOS, 2014, p. 62).

A contratação de trabalhadores terceirizados pelo serviço público, resulta, portanto, numa ameaça real aos regimes jurídicos adotados na Administração Pública brasileira, não só pela possibilidade de ocorrer algum tipo de infringência à legislação pertinente, mas, sobretudo, pelos riscos decorrentes desse processo, conforme salienta Ferraz, ao relatar as principais distorções que o Ministério Público do Trabalho conseguiu identificar:

O que o Ministério Público do Trabalho já identificou:

- As estatais contratam terceirizados em vez de empregar pessoas que prestaram concurso público

- Estão mais sujeitos a acidentes de trabalho

- Não têm o mesmo treinamento dos funcionários efetivados 
- Os terceirizados recebem salários inferiores e não têm os mesmos direitos que os efetivos (contratados com carteira) (FERRAZ, 2006, p. 252).

Ainda de acordo com o referido autor, "entre $30 \%$ e $50 \%$ dos funcionários das estatais são terceirizados, estima a Coordenadoria Nacional de Combate às Irregularidades Trabalhistas na Administração Pública, ligada ao Ministério Público do Trabalho" (FERRAZ, 2006, p. 252). Esse elevado número da terceirização no serviço público é decorrente, principalmente, das pressões a que o gestor público é submetido, para não infringir o rigor da Lei Complementar $n^{\circ}$ 101/2000, conhecida como Lei de Responsabilidade Fiscal (LRF), e vir a sofrer as sanções cabíveis. Essa condição ocorre porque, as despesas com a terceirização não são contabilizadas como gastos com pessoal, o que auxilia o gestor público a manter o equilíbrio das contas públicas, além de representar um ganho em termos de redução de custos, pois como afirma Pochmann (2007, p. 02), "um trabalhador terceirizado ganha, em média, metade do não terceirizado". Entretanto, Miraglia adverte que:

\begin{abstract}
A terceirização deve constar, como toda despesa pública, da Lei de Responsabilidade Fiscal, estando o órgão público contratante obrigado a prestar contas da mesma. Infere-se que a terceirização surge como "solução enganosa" à diminuição dos gastos públicos, pois apenas transfere a contratação (MIRAGLIA, 2008, p. 174).
\end{abstract}

As ameaças que o processo de terceirização representa para os regimes jurídicos adotados pela Administração Pública são muito bem traduzidas no dizer de Silva et al que assim se manifestam:

\begin{abstract}
A forma encontrada até hoje para suprir as necessidades de serviços, pela contratação de mão-de-obra terceirizada constitui uma ameaça à boa gestão pública, tanto pela ausência de garantias de qualidade dos serviços quanto pela baixa eficiência dos métodos de contratação dos empregados. Hoje terceirização no setor público brasileiro é sinônimo de contratação de "cabeças" e homens-hora, modalidades que não proporcionam ao administrador público a melhor gestão dos serviços executados" (SILVA, et.al., 2012, p. 10).
\end{abstract}

Nesse mesmo sentido de raciocínio, Resende, conforme já fora anteriormente explicitado, elenca, como possíveis ameaças à aplicação do processo de terceirização na Administração Pública: 
a) Precarização dos direitos trabalhistas em geral e rebaixamento de salários, em especial;

b) Precarização do meio ambiente de trabalho, ante a pulverização dos trabalhadores;

c) Enfraquecimento do movimento sindical, mediante a dispersão dos trabalhadores em inúmeras empresas pequenas, sem qualquer preocupação com sua integração social (RESENDE, 2014, p. 230-231).

\section{CONCLUSÃO}

A Súmula $n^{\circ} 331$ do TST, que define quais atividades podem ser terceirizadas, bem como estabelece as responsabilidades perante eventuais faltas ao cumprimento das garantias devidas ao trabalhador, se reveste, na prática, no único instrumento normativo legal a disciplinar as relações entre empresas tomadoras e prestadores de serviços.

Por outro lado, a obrigatoriedade de obedecer à Lei de Responsabilidade Fiscal (LRF) e a dificuldade alegada de se contratar em consonância ao disposto nos regimes jurídicos aplicados na Administração Pública e ao preceito constitucional que obriga a aprovação em concurso público para investidura no serviço público, seja como servidor estatutário ou celetista, de acordo com o disposto no artigo 37, inciso II da Constituição Federal de 1988, tem levado o gestor público a valer-se do processo de terceirização, como tentativa para evitar excessos de gastos públicos, o que ensejaria sanções, face o disposto na LRF.

A terceirização excessiva na Administração Pública não decorre de um planejamento estratégico, elaborado pelo Poder Público, cujo fito deveria ser o de aperfeiçoar o serviço público. O processo, na verdade, é consequência de uma legislação que limita gastos e estabelece condições para a contratação dos servidores, forçando o gestor público a se valer do expediente da terceirização, apesar de o país não dispor de um regramento consistente que discipline as relações trilaterais entre empresas tomadoras do serviço, empresas prestadoras do serviço e o trabalhador, cujos resultados concretos não resultam em ganhos objetivos para o Estado.

Apesar de alguns doutrinadores considerarem vantajosa a aplicação da terceirização em determinadas atividades na Administração Pública, por possibilitar que o Estado dediquese às atividades que lhe são pertinentes, além de poder solucionar, ainda que 
temporariamente, a falta de pessoal no serviço público, a sua prática descontrolada e intensiva penaliza as instituições públicas, na medida em que esta passar a se tornar completamente dependente dos serviços executados pelas empresas prestadoras dos serviços.

Essa dependência se torna inevitável, já que o Estado opta por abrir mão de realizar concurso público para contratação de pessoal, que poderia treiná-lo e capacitá-lo, priorizando a contratação de empresas prestadoras de serviços para sublocar mão-de-obra, correndo o risco de ter em seus quadros profissionais sem a devida preparação e competência para exercer as funções públicas.

Dessa forma, a prática da terceirização no setor público, que tem especificidades distintas do setor privado, por exemplo, a não visar lucro em suas atividades, além de provocar uma incômoda dependência ao prestador dos serviços, pode resultar, ainda, em aumento de custos na transação, afetando a competência essencial da Administração Pública.

A utilização indiscriminada e intensa do processo de terceirização na Administração Pública constitui-se, ainda, em grave e séria ameaça aos regimes jurídicos aplicados no setor público, que deixam de ser aplicados nas relações estabelecidas entres os órgãos públicos e os trabalhadores terceirizados, já que os mesmos são contratados pelas empresas prestadoras de serviços, de quem recebe salários e demais benefícios legais.

Observa-se, ainda, em função dessa prática cada vez mais frequente, uma forte tendência de burla à Constituição Federal de 1988, especialmente ao inciso II do artigo 37, que obriga a aprovação em concurso público para a investidura em cargo ou emprego público.

A conclusão a que se chega é que a utilização do expediente da terceirização não se traduz em ganhos para o setor público, resultando, por conseguinte, em um processo mais desvantajoso do que vantajoso para a Administração Pública.

Do mesmo modo, conclui-se que os regimes jurídicos aplicados na Administração Pública sofrem forte ameaça por parte do processo de terceirização, principalmente porque o Brasil carece de uma legislação clara e objetiva, que defina quais e em que condições esse expediente pode ser aplicado no setor público.

\section{REFERÊNCIAS}

CARVAlHO FILHO, José dos Santos. Manual de Direito Administrativo. 27 ed., São Paulo: Editora Atlas, 2011. 
DELGADO, Maurício Godinho. Curso de Direito do Trabalho. $13^{\text {a }}$ ed., São Paulo: Editora LTr, 2014.

DIEESE. O Processo de Terceirização e seus Efeitos sobre os Trabalhadores no Brasil. Rio de Janeiro, 2013. Disponível em: <www3.mte.gov.br/observatório/Prod03_2007>.pdf. Acesso em: 18 jun. 2016.

FERRAZ, Fernando Basto. Terceirização e Demais Formas de Flexibilização do Trabalho. São Paulo: Editora LTr, 2006.

FLORES DOS SANTOS, Diogo Palau. Terceirização de Serviços pela Administração Pública: Estudo da Responsabilidade Subsidiária. $2^{a}$ ed., São Paulo: Editora Saraiva, 2014.

JUSTEN FILHO, Marçal. Curso de Direito Administrativo. 10 a ed., São Paulo: Editora Revista dos Tribunais, 2014.

MIRAGLIA, Lívia Mendes Moreira. A Terceirização Trabalhista no Brasil. $1^{a}$ ed., São Paulo: Editora Quartier Latin, 2008.

PEREIRA, Leone. Direito do Trabalho. $3^{\text {a }}$ ed., São Paulo: Editora Revista dos Tribunais Ltda, 2013.

RESENDE, Ricardo. Direito do Trabalho Esquematizado. 4ª ed., São Paulo: Editora Método, 2014.

SANTOS, Rodrigo Coimbra. Relações Terceirizadas de Trabalho. $1^{\mathrm{a}}$ ed., $3^{\mathrm{a}}$ tr., Curitiba: Juruá Editora, 2008.

SILVA, Ricardo Margonari da et al. A Terceirização no Setor Público Brasileiro: Um estudo acerca da terceirização na Universidade Federal de Uberlândia e seus impactos na qualidade do ensino. 2012. Disponível em <www.histedbr.fe.unicamp.br/.../artigo_simposio_3_560_ricardo_margon>. Acesso em: 18 jun. 2016. 